\title{
Intelectuales y democracia Notas a propósito de los encuentros de Maryland
}

\author{
Intellectuals and democracy \\ Maryland Meeting Notes
}

\section{Martina Garategaray}

Centro de Historia Intelectual-Universidad Nacional de Quilmes,

CONICET/Universidad de Buenos Aires martina.garategaray@gmail.com

\begin{abstract}
Resumen: Entre 1984 y 1994, cinco reuniones de intelectuales latinoamericanos convocados por Saul Sosnowski se llevaron a cabo en la Universidad de Maryland para discutir "Cultura y redemocratización en el Cono Sur". Si bien en cada reunión se discutieron temas específicos que formaron la cultura política de Argentina, Uruguay, Brasil, Chile y Paraguay, respectivamente, creemos que es posible conectar estas reuniones por temas o temas recurrentes, y también porque estos temas se plantearon en un lenguaje político común En este sentido, este documento busca explorar estas reuniones como entradas para el debate políticointelectual del "retorno a la democracia" y las coordenadas comunes que delimitaron las posibilidades y limitaciones de las democracias nacientes.
\end{abstract}

Palabras clave: Democracia, intelectuales, Maryland.

\begin{abstract}
Between 1984 and 1994, five meetings organized by Saul Sosnowski to discuss "Culture and redemocratization in the Southern Cone" with Latin American intellectuals were held at the University of Maryland. Although in each meeting particular issues on the political culture of Argentina, Uruguay, Brazil, Chile and Paraguay were discussed, we believe that it is possible to connect these meetings because of the recurrence of topics and the common political language used. In this sense, this work seeks to explore these encounters as entries to the political-intellectual debate of "the return to democracy", and indicators of the common coordinates that delimited the possibilities and limitations of the newborn democracies.
\end{abstract}

Keywords: Democracy, Intellectualls,

Maryland. 


\section{Introducción}

Entre 1984 y 1994 intelectuales de un amplio abanico ideológico y de varias especialidades como las artes, las letras, las humanidades y las ciencias sociales fueron convocados por Saúl Sosnowski a una serie de encuentros que bajo la consigna "Cultura y redemocratización en el Cono Sur", se realizaron en la Universidad de Maryland, en Estados Unidos. ${ }^{1}$ A pesar del asumido antiimperialismo de muchos de los invitados, Maryland se convirtió en el punto de reunión entre los que se fueron y los que se quedaron, permitiendo un diálogo inimaginable en sus países de origen.

En estas páginas buscamos explorar esos diálogos como mojones de los debates que estructuraron "la vuelta a la democracia" y como entradas al pensamiento políticointelectual de la segunda mitad del siglo XX. Si bien los encuentros no fueron pensados de antemano como partes de un mismo proyecto, el hecho de que se sucedieran casi en el orden cronológico en el que se dio la "vuelta" en cada uno de los países del Cono Sur, y que ciertas temáticas aparecieran de modo recurrente o fuesen presentadas a partir de una matriz argumental similar, nos permite leerlos haciendo uso de una estrategia comparada que busca dar cuenta de la transnacionalidad de ciertas ideas y debates. ${ }^{2}$

Partimos de una perspectiva y línea de investigación en la que venimos trabajando que se propone, desde el cruce entre la nueva historia de las ideas -con su énfasis en el contexto, la temporalidad y las formas de lo político-, y la teoría política contemporánea -en clave pos-fundacional con su hincapié en la contingencia y la indeterminación-, analizar el contexto político intelectual sobre el que se erigió el debate público en los años ochenta/noventa que comúnmente se asocian a "la transición democrática" y al pasaje del paradigma de la violencia/revolución al de la

\footnotetext{
${ }^{1}$ Los encuentros fueron auspiciados por el Centro de Estudios Latinoamericanos que fundó y dirigió Saúl Sosnowski reconocido especialista en crítica literaria y fundador de la revista Hispamérica. Los encuentros fueron por países: en 1984 tuvo lugar el encuentro argentino, en 1986 el uruguayo, en 1988 el brasileño, en 1991 el de Chile y en 1994 el paraguayo. Todos ellos fueron posteriormente publicados como libros.

${ }^{2}$ En los últimos años la perspectiva transnacional ha ganado terreno como nueva mirada comparativa que buscando romper con la categoría del estado nación, el etnocentrismo y los modelos binarios o duales -tan comunes en las perspectivas comparativas-, se muestra atenta al movimiento entre regiones, lugares y sitios, a las relaciones y las redes, la circulación y las conexiones tanto entre cosas, personas, ideas e instituciones. Sobre estas cuestiones puede consultarse una variada bibliografía que va de Bayly et al. 2006; Conrad, 2016 a Gorelik, 2004 y Lastra, 2018.
} 
democracia/orden ${ }^{3}$. Nos interesan esos años porque estimamos que en los mismos se jugaron sentidos sobre la política y lo político que aún hoy son revisitados en las discusiones sobre las democracias modernas y porque volver sobre los mismos es recuperar muchos de los debates y cuestionamientos que no fueron hegemónicos, que no impactaron directamente en la agenda política de las transiciones, pero que nos revelan el carácter contingente y discutible de la política moderna señalando, entre otras cosas, que varios caminos se presentaban como posibles e imaginables. Hemos elegido para interrogar esos años a ciertos espacios de diálogo y polémica como revistas, encuentros, seminarios y congresos, porque en los mismos se cristalizaron las posiciones públicas de políticos e intelectuales revelando los pliegues del suelo argumental de, lo que hemos denominado, el lenguaje político de una época ${ }^{4}$.

En este trabajo particular nos centraremos en los llamados "encuentros de Maryland" para explorar cómo esos encuentros fueron no sólo índices de los tópicos centrales que se discutieron en cada uno de los países, en los años de la redemocratización, sino también, índices de ciertas tramas argumentales comunes. Hubo cuestiones que se impusieron en cada uno de los encuentros dando cuenta del modo en el que esos temas se inscribían en la historia político cultural nacional, pero también varios de estos tópicos, aunque asumiendo modulaciones particulares, se repitieron en los distintos encuentros poniendo de manifiesto la dimensión regional y compartida de ciertos debates. Es nuestra hipótesis que esta recurrencia de temas e ideas se erige sobre un suelo argumental común, y es esa trama argumental paradojal la que le confiere cierta unidad a la región y no la simple aparición de los mismos conceptos en los debates.

En la reedición del libro sobre el encuentro argentino, Saúl Sosnowski afirmó, desde el nuevo prólogo, que la utilidad de volver a publicar este volumen lo ubicaba en el incómodo lugar de la actualidad: saber que ésta todavía no es una época superada (SOSNOWSKI, 2014: 9). Retomamos sus palabras porque nos parece que es aquella una incomodidad muy productiva en la medida que, si ese momento no se nos presenta

\footnotetext{
${ }^{3}$ Sobre una perspectiva teórico-metodológica para reflexionar sobre las transiciones democráticas en América Latina véase: (GARATEGARAY \& REANO 2019-2020, 2018, 2017).

${ }^{4} \mathrm{Si}$ por lenguaje entendemos un entramado que no es cerrado, completo, ni acabado y que no se identifica con un conjunto de enunciados o conceptos que hacen sistema sino más bien con un modo de construir los argumentos, un modo de relacionar y encadenar ideas y representaciones, creemos que es posible identificar un lenguaje de los años ochenta que estuvo signado por el paso de la revolución a la democracia, con todo lo que estos imaginarios supusieron para los actores de la época. Sobre los lenguajes políticos véase (PALTI, 2005 y PALTI, 2018).
} 
como una instancia cerrada o concluida del pasado reciente, es porque puede ser revisitado para ahondar en las fisuras del entramado político cultural que nos permita una mejor comprensión de ese período y de las aún debatidas democracias en el Cono Sur.

\section{La Argentina dicotómica}

A un año de la victoria electoral del radicalismo de la mano de Raúl Alfonsín, se realizó entre los días 2, 3 y 4 de diciembre de 1984 el encuentro "Represión y reconstrucción de una cultura: el caso argentino". 5 En el mismo se abordaron varias cuestiones relativas a la nueva experiencia democrática, a la persistencia de una cultura autoritaria y al pasado reciente. Nos interesa detenernos en la lectura crítica que se realiza del pasado reciente, una lectura tramada también por los debates sobre el rol del intelectual y la experiencia del exilio, porque la misma fue un tema central en ese encuentro convirtiéndose también en una de las marcas del debate político intelectual argentino de los años ochenta. Un debate que no sólo se centró en lo que representó la dictadura militar, sino también los años previos al golpe y la vía revolucionaria ${ }^{6}$.

El filósofo José Pablo Feinmann reconstruyó el pasado identificando tres momentos históricos en la construcción de un discurso ideológico que expresaba, en el

\footnotetext{
${ }^{5}$ A pesar de haber sido el primer encuentro se publica después del libro sobre Uruguay en 1988. El encuentro estuvo estructurado de este modo. Un bloque de contextos en el que participaron: Hipólito Solari Yrigoyen, Tulio Halperín Donghi y Mónica Peralta Ramos, moderado por Richard Morse. Un bloque de cultura y poder del que participaron José Pablo Feinmann, León Rozitchner y Beatriz Sarlo, moderado por Tomás Eloy Martínez. Un tercer bloque sobre Literatura que integraron: Luis Gregorich, Jorge Lafforgue, Juan Carlos Martini, Noé Jitrik y que moderó Saúl Sosnowski; un bloque titulado: las orillas de los exilios, en el que disertaron: Tomás Eloy Martínez, Osvaldo Bayer y Liliana Heker, que comentó Adolfo Prieto y moderó Jorge Balán. Y un último bloque sobre procesos de debate y reconstrucción del que participaron Kive Staiff, Luis Gregorich, Hipólito Solari Yrigoyen y Santiago Kovadloff y que moderó Sosnowski. Fueron invitados pero no pudieron asistir: Manuel Antín, Aída Bornik, Carlos Matínez Vidal y Osvaldo Soriano. Se publicaron los trabajos de Hipólito Solari Yrigoyen, Tulio Halperín Donghi, Mónica Peralta Ramos, José Pablo Feinmann, Beatriz Sarlo, Luis Gregorich, Juan Carlos Martini, Noé Jitrik, Jorge Lafforgue, León Rozitchner, Tomás Eloy Martínez, Liliana Heker, Osvaldo Bayer y Santiago Kovadloff (SOSNOWSKI, 2014).

${ }^{6}$ Sobre la autocrítica política e intelectual pueden verse los 14 números (en realidad fueron 13) de la revista Controversia para el Examen de la Realidad Argentina, publicada entre octubre de 1979 y agosto de 1981 en el exilio mexicano. Dirigida por Jorge Tula y un consejo de redacción integrado por: Carlos Abalo, José Aricó, Sergio Bufano, Sergio Caletti, Nicolás Casullo, Ricardo Nudelman, Juan Carlos Portantiero, Héctor Schmucler y Oscar Terán. En sus páginas quedaron las marcas de un diálogo fecundo entre la tradición de izquierda socialista y peronista a partir de la revisión crítica de lo que fueron las estrategias armadas en la acción de una política de sectores de la izquierda argentina. De ahí que se llamara tanto a discutir la derrota como a construir una alternativa para la argentina posdictatorial.
} 
modo de la verdad, una práctica política diferenciada. Se refirió a las distintas verdades que fueron hegemónicas en el pasado reciente: la verdad liberal, la verdad de la Juventud Peronista 1970-1973, la verdad de la seguridad nacional 1976-1983, y la verdad de la democracia que, lejos de una mirada absoluta "implica la creación de un espacio de la tolerancia en el que las distintas verdades de los adversarios políticos no se enfrenten en términos de guerra" (FEINMANN, 2014: 132). A pesar de su énfasis en la dimensión de diálogo y persuasión que escondía "la verdad democrática", el hecho de apelar a la noción de verdad y reivindicar el pasado setentista suscitó críticas y condenas. Beatriz Sarlo, directora de la prestigiosa revista de crítica cultural Punto de $V_{i s t a}{ }^{7}$, encontraba allí una seria dificultad porque "en el pasado reciente los argentinos nos hemos dedicado a politizar la historia y a leer en tiempo presente los hechos del pasado" (SARLO, 2014: 135). A esta mirada negativa con respecto a la centralidad de la política, Sarlo agregaba que los hombres habían sido responsables de lo sucedido en el pasado reciente por sostener verdades e ideales que condujeron a la muerte; desplazaba así la pregunta por "qué nos hizo el autoritarismo", a "qué hicimos nosotros, enfermos también de absoluto" (SARLO, 2014: 136). De algún modo su argumento, que se presentaba de un modo potente y provocador, se ubicaba en las antípodas de la posición de Feinmann y volvía sobre un debate que en otros espacios también se había desplegado entre las tradiciones peronista y socialista por las representaciones del pasado; mientras algunos buscaban recuperar la relación de la política y la militancia en la historia reciente, otros criticaban la politización de los años setentas ${ }^{8}$.

Desde principios de los ochenta el exilio fue uno de los tópicos que más diferencias venía suscitando en el campo literario e intelectual y las expresiones en el encuentro, desde la autocrítica o el testimonio, volvieron sobre la controversia ${ }^{9}$. A pesar

\footnotetext{
${ }^{7}$ La revista Punto de Vista se publicó en Buenos Aires entre marzo de 1978 y abril de 2008. En esos 90 números fue dirigida por Beatriz Sarlo y contaba en su consejo de dirección con intelectuales como: Carlos Altamirano, María Teresa Gramuglio, Hilda Sábato, Hugo Vezzetti, José Aricó y Juan Carlos Portantiero (estos últimos se incorporan recién en 1983 al regresar del exilio mexicano imprimiéndole su mirada a la revista). Adrián Gorelik se suma en 1992 y en 1995 aparece un Consejo asesor integrado por Oscar Terán, Raúl Beceyro, Jorge Dotti, Rafael Filippelli y Federico Monjeau. Definida como una revista cultural Punto de Vista fue expresión de la intelectualidad de izquierda en esos años.

${ }^{8}$ Los debates entre los miembros de las revistas Unidos y Punto de Vista, dan cuenta de estos clivajes y posicionamientos en el campo político-cultural. Mientras el peronismo se mostraba más receptivo con las experiencias del pasado reciente buscando recuperar la épica y la liturgia militante y revolucionaria, el socialismo en las voces de Sarlo o Terán, se mostraba condenatorio con respecto al mismo. Véase Garategaray (2018).

${ }^{9}$ Nos referimos a la polémica entre Liliana Heker y Julio Cortázar, que se llevó a cabo entre 1981 y 1983 en las páginas del Ornitorrinco y la desatada a partir de la nota de Luis Gregorich "La Literatura dividida"
} 
del intento por escapar de las polémicas que en un pasado no lejano se suscitaron y que tuvieron a varios de estos intelectuales como protagonistas, el corte dicotómico entre los que se fueron y los que se quedaron, entre los que lucharon y colaboraron, entre la literatura dentro y fuera del país, estuvo presente en casi todas las intervenciones. Si Gregorich, buscando desandar el camino de su controversial artículo buscó afirmar en esta oportunidad que el exilio no debía ser considerado un parte aguas, puesto que no había diferencia entre lo que se escribió dentro o fuera del país ni buena o mala literatura, fue igualmente criticado. Esto ponía en evidencia dos cuestiones, lo sensible que era todavía el tema para los invitados, como también la persistencia de una matriz argumental similar para leer ese pasado.

Si como afirmaba Sarlo el exilio había fracturado el campo intelectual entre un adentro y un afuera, reconocer este corte como una definición identitaria era no sólo asumir el clivaje que intentó establecer la propia dictadura para debilitar al campo intelectual (SARLO, 2014: 145), sino poco productivo para discutir el futuro de la cultura democrática. No obstante, estas divisiones seguían presentes en las argumentaciones. De un modo u otro la persistencia de estas oposiciones: exilio/insilo, adentro/afuera, dictadura/democracia, que se reproducen en todas las intervenciones, nos dice mucho sobre el dualismo de la cultura argentina como también del modo de dirimir las diferencias. Mientras se afirmaba la necesidad de consenso, de respetar las diferencias y estimular el diálogo, tuvo lugar, al decir de Sosnowski, "la discusión febril de las discrepancias" (SOSNOWSKI, 2014: 31).

La ponencia de Santiago Kovaldoff cerró el libro y bien podría ser leída como un corolario de lo allí discutido. En la misma afirmaba Kovaldoff que "nos gobiernan las dicotomías" (KOVALDOFF, 2014: 307) pero, y aquí descansa la paradoja de la realidad argentina, la democracia que tanta falta hace no podía ser fruto sino de una resuelta voluntad de convergencia. De este modo la búsqueda del consenso y la unidad se convertían en una necesidad para la consolidación de la democracia y una apuesta hacia el futuro.

de 1981. Ambas expresaron las tensiones y discusiones entre los escritores e intelectuales que se fueron y los que se quedaron en el país. Cruzándose también con interpretaciones sobre la buena o mala literatura. Para un análisis de estas polémicas véase De Diego (2001). 


\section{El Uruguay de los mitos}

En 1986 se realizó el segundo encuentro: "Represión, exilio y democracia”, en el que se reunieron los uruguayos que pasaron por diversas experiencias como la cárcel, el exilio, el insilio y que se reencontraron en democracia ${ }^{10}$. Fue común en la reflexión de los participantes la idea de la continuidad del pasado en el presente -ya sea entre el pasado previo al golpe militar y la flamante democracia, como entre la cultura durante la dictadura y la cultura en los primeros años de la democracia-, como también la de un pasado que podía ser recuperado.

En varias de las intervenciones la historia uruguaya era presentada en una línea de continuidad con respecto al pasado reciente en la que el presente político de desacuerdos entre el Partido Colorado y el Partido Blanco, con la emergencia de la coalición que representaba el Frente Amplio, se explicaba en la tradición política uruguaya de incapacidad de unión de los tradicionales partidos como también de coaliciones (KAUFMAN, 1987). En la misma línea la crisis no habría sido desatada por el golpe militar sino que databa desde fines de los años '60 cuando Uruguay perdió su civilismo junto a su bienestar económico, causas que desencadenaron la crisis política y la violencia (WEINSTEIN, 1987).

Junto a estas miradas, también encontramos cierta continuidad en el plano de la cultura entre un antes y un después del golpe (ACHÚGAR, 1987) que explicaba tanto que la producción cultural continuara dentro y fuera del país (GALEANO, 1987) como que no se hayan producido divisiones tajantes que permitían hablar de una sola cultura no cómplice con la dictadura que se expresó en la cárcel, la calle y el exilio (YÁNEZ, 1987). Si algunos participantes introdujeron matices, afirmando como Porzecanski la especificidad de una narrativa que se produjo durante la dictadura, esta inflexión no atentaba contra la defendida unidad de los artistas e intelectuales tanto dentro como fuera del país.

\footnotetext{
${ }^{10}$ En este caso fueron cinco los paneles. Contextos, moderado por Azucena Berruti y en el que participaron: Martín Weinstein, Edy Kaufman y Juan Rial. Le siguió Cultura y Poder, moderado por Luisa Popkin con la participación de: Mauricio Rosencof, Ruben Yañez, Eduardo Galeano, Leo Masliah. El panel sobre Literatura fue coordinado por Tomás Eloy Martínez y disertaron: José Pedro Díaz, Teresa Porzecanski, Hugo Verani, Lisa Block de Behar. El cuarto panel "Las orillas de los exilios" estuvo integrado por Hugo Achúgar, Alvaro Barros Lemez, Jorge Ruffinelli e Hiber Conteris. Y, en el último panel, Las dimensiones comparadas del sur, moderado por Peter Hakim, expusieron Juan Corradi, Joan Dassin, Carina Perelli y Bernardo Subercaseaux. Véase Sosnowski (1987).
} 
En esta presencia del pasado en el presente, los mitos, entendidos como un recuerdo que podía ser rescatado para la reconstrucción, ocuparon un lugar privilegiado en las argumentaciones desplegadas en Maryland. La apelación a los mitos aparecía en el Uruguay posdicatorial como un modo de recortar el pasado nacional y fundar las renacientes democracias. En palabras de Sosnowski: "en los discursos se alegaba, se presuponía -con pocas excepciones-, la existencia de un tronco esencial que justificaba variantes de régimen pero no -por lo menos aún no- una transformación radical que exigiera el abandono final de aquello tan caro a la mitificación nacional" (SOSNOWSKI, 1987: 17).

Si bien la dimensión mítica recorrió varias de las interpretaciones, fue el artículo del politólogo Juan Rial el que puso en el centro del análisis a los mitos políticos y las utopías en Uruguay. Afirmaba que todas las sociedades construyen sus mitos para poder leer el mundo como un continuo relacionando pasado, presente y futuro, y que la sociedad uruguaya, "a pesar de estar tironeada constantemente por el racionalismo liberal y el marxista", no era la excepción (RIAL, 1987: 69). Rial reflexionó de un modo crítico sobre los mitos que habrían estructurado al Uruguay en los años '50, que reforzaban la diferencia como superioridad uruguaya, el conservadurismo y el temor al conflicto social, y que fueron importantes en la construcción de la identidad nacional y se tradujeron en slogans "como el Uruguay no hay", "país modelo", la "Atenas del Plata".

Más allá de las formas concretas que fueron asumiendo estos mitos, sostiene Rial que frente a la crisis de los años cincuenta primero, y al golpe después, los mitos básicos se reafirmaron y se preguntaba, de cara al fin del régimen dictatorial y al proceso de redemocratización: “¿Se mantendrían o no los mitos básicos que conformaban el imaginario social? (RIAL, 1987: 85) y respondía que por lo menos dos mitos, que se presentaban como nuevos, se mantenían: el del Uruguay democrático, dónde el consenso debía primar a toda costa, y el de la "uruguayidad" como reafirmación de la particularidad y la diferencia con respecto al resto de América Latina y Europa. A pesar de lo desgastados de los mitos nacionales y de lo identificables con experiencias críticas del pasado uruguayo, decía Rial que había una necesidad de recrearlos aunque fuera de modo artificioso.

En la misma línea la socióloga Perelli se acercó al modo en el que esos mitos eran repuestos en el presente a través de la memoria, En sus palabras "la memoria constituye un mito fundacional [...] que se actualiza simultáneamente en el constante 
recrearse de las identidades y en la posesión o apropiación de pasado, futuro por el pensamiento presente" (PERELLI, 1987: 322). De ello se desprende que al ser la memoria el sentido del mundo en el que vivimos, su recuperación mítica no era vista como algo negativo pero cuyos sentidos y, podríamos agregar sus usos políticos, debían develarse y cuestionarse.

A diferencia del encuentro argentino, en esta reunión no tuvo lugar la feroz polémica entre exiliados y no exiliados (ni el exilio fue un tema importante sino más bien el desexilio), no se reconoció una cultura cómplice durante los años de dictadura, no hubo autocrítica, y no afloraron discrepancias. Tal vez como sostiene Sosnowski, es posible pensar que esta unidad (entre el adentro y el afuera, entre la cultura en dictadura y después) fue el correlato de afirmar la continuidad con el pasado previo al golpe, y la adhesión a los mitos fundantes. Una recuperación del pasado que permitía encontrar un linaje al que encadenar la nueva democracia ${ }^{11}$.

\section{Brasil y la memoria histórica}

En 1988 tuvo lugar el tercer encuentro titulado "O trânsito da memória" en el que se tematizó la redemocratización brasileña ${ }^{12}$. La peculiaridad de Brasil, signada por una prolongada transición a la democracia que se correspondía con una larga y temprana dictadura, y por la inesperada muerte de Tancredo Neves antes de asumir y su reemplazo por José Sarney, imprimió cierto desaliento al debate intelectual. El pasado reaparecía en el debate pero, no era ya el pasado previo a la dictadura, sino un pasado presente tramado en y teñido de autoritarismo.

\footnotetext{
11 Álvaro di Giorgi sostiene, en su investigación sobre el discurso de Julio María Sanguinetti que es posible observar (y cita Álvaro Rico) una estrategia continuista de restauración de los relatos, creencias y mitos fundantes de Uruguay, y que esa estrategia puede ser caracterizada como una retropía, una apuesta hacia el futuro pasado. En Di Giorgi (2010).

${ }^{12}$ Participaron de este encuentro, que no estuvo articulado en bloques,: Joaquim Alvez de Aguiar, Ivan Ângelo, Jean Claude Bernadet, Maria do Carmo Campelo de Souza, Técio Lins e Silva, Carlos Eduardo Lins da Silva, Ignacio de Loyola Brandão, Fábio Lucas, Ana Maria Machado, Sergio Miceli, Yan Michanski, Walnice Nogueira Galvão, Nélida Piñón, Darcy Ribeiro, Silvano Santiago, Muñiz Sodré, Maria da Conceição de Almeida Tavares y Gilberto Velho aunque no todos publicaron sus trabajos en el libro compilado por Saúl Sosnoswski y Jorge Schwartz que reunió varias intervenciones como artículos. Se publicaron los trabajos de: Joaquim Alvez de Aguiar, Ivan Ângelo, Jean Claude Bernadet, Carlos Eduardo Lins da Silva, Ignacio de Loyola Brandão, Fábio Lucas, Ana Maria Machado, Sergio Miceli, Yan Michanski, Walnice Nogueira Galvão, Nélida Piñón, Muñiz Sodré, Maria da Conceição de Almeida Tavares y Gilberto Velho. Véase Sosnowski \& Schwarz (1994). El encuentro se realizó en 1988 pero se publicó en 1994.
} 
Quizás el texto de Joan Dassin presentado en el encuentro uruguayo fue el disparador para pensar el tema/problema de la memoria en Brasil y la persistencia del pasado. Dassin partió de la tesis de Florestán Fernández que afirmaba que no había habido ruptura sino continuidad con el autoritarismo. En palabras de Dassin: "La transición fruto de una larga y controlada liberalización, ha sido conservadora y elitista en carácter, representando un acuerdo entre las clases dominantes y el liderazgo militar" (DASSIN, 1987: 305). Y en este clima, la cultura no se había preocupado por temas de memoria histórica. Por un lado porque el Frente que por 20 años había unido a los intelectuales en contra de la dictadura se fragmentó en el primer año de la Nova República como resultado de que los intelectuales y los artistas que lo conformaron tomaron claras actitudes frente a temas políticos o estéticos. Por el otro, porque tampoco hubo una política de memoria sino un acuerdo en olvidar por parte de la elite política y los militares, como también por la Nueva Izquierda que no quiso analizar en profundidad las causas del golpe militar de 1964. A pesar de su falta, la memoria sobre el pasado reciente apareció como necesaria para poner un freno al avance autoritario y como la contracara del impulsado olvido por parte de la elite dirigente.

Esta idea en torno a la persistencia del pasado fue común a todos los expositores que reconocían de un modo más bien continuista el retorno a la institucionalidad democrática en 1985. Gilberto Velho reconocía al Brasil como violento desde sus orígenes y no como una novedad introducida por los militares (VELHO, 1994). No obstante, esto no quería decir para el antropólogo que la dictadura no hubiera intensificado esta situación sino que el temprano ingreso de Brasil al autoritarismo dejó profundas marcas en la cultura. Para el escritor Ignácio de Loyola Brandão mientras el golpe de 1964 definió un corte en la historia de Brasil, 1985 representaba una frontera nebulosa que llevó a caracterizar a la transición como "un régimen indefinido" (DE LOYOLA BRANDAO, 1994). Esta indefinición fue vista por la economista Maria da Conceição Tavares como una continuidad con el régimen anterior: "la política económica de 1985 continúa autoritária" (TAVARES, 1994: 19), y por ello la transición fue caracterizada como un autoritarismo, pero sin dictadura. Este señalamiento fue importante en los años de la transición pero central en el debate político e intelectual posterior que reafirmó el continuismo de las prácticas autoritarias en democracia ${ }^{13}$.

\footnotetext{
${ }^{13}$ Uno de los argumentos más extendidos entre la intelectualidad brasileña es el de reconocer que la llamada transición "por lo alto", es decir como resultado de la "conciliación" entre grupos políticos liberales progresistas y conservadores, católicos tradicionalistas y militares, excluyó a los sectores
} 
Lo que aparecía como una constante en el encuentro era el reconocimiento de que aún en la transición democrática el autoritarismo era una de sus permanencias, por lo que la experiencia de la transición brasileña debía enfrentar los mismos problemas del pasado. En esta mirada, en la que el pasado se hacía presente, el llamado a una memoria histórica era fundamental para la construcción de un futuro democrático que se opusiera al temido olvido. En otras palabras, frente a la continuidad con el régimen dictatorial, ya sea porque ciertas políticas se mantenían o porque la democracia no había logrado desterrar prácticas estableciendo un corte tajante con el pasado reciente, se apelaba a la memoria como forma de la ruptura. La memoria aparecía en los argumentos de los participantes no como una estrategia asumida por los intelectuales de la cultura ni como una política de los primeros años del gobierno democrático, sino como una necesidad. De este modo, la memoria que se proyectaba al futuro podía ser vista como garantía y salvaguarda de la democracia.

\section{El Chile paradójico}

En diciembre de 1991 tuvo lugar el encuentro "Cultura, autoritarismo y redemocratización" ${ }^{14}$. En esa oportunidad Saúl Sosnowski, Manuel Antonio Garretón y Bernardo Subercaseaux, presentaron los desafíos de la cultura en la "vuelta a la democracia" de modo paradojal. Podríamos desglosar su argumento en dos grandes paradojas. La primera consistía en que, si bien la dictadura se convirtió en el enemigo de la creación y la libre expresión de ideas a través de la intervención de las universidades, la censura de los medios de comunicación, la persecución de creadores, artistas e intelectuales, no desarrolló un proyecto cultural propio y, curiosamente en esos años, hubo una gran productividad en vez de un "apagón cultural” (SOSNOWSKI, GARRETÓN \& SUBERCASEAUX, 1993: 8). La segunda paradoja, se refería a que las

populares de muchas decisiones generando "el continuismo de prácticas antidemocráticas" (DE SOUZA NEVES \& ROLIM CAPELATO, 2008: 202).

14 El mismo se estructuró en cinco partes, una primera parte titulada Historia y transformaciones culturales: el contexto, con intervenciones de: Bernardo Subercaseaux, Alfonso Caledrón, Luisa Ulibarri, Nelly Richard. Una segunda parte: Dos décadas de comunicación y cultura: 1970-1990 con textos de Jorge Edwards, Grígor Rojo, María de la Luz Hurtado, Giselle Munizaga. Una tercera parte: Hacia la incorporación de los márgenes, en la que participaron: Soledad Bianchi, Sonia Montecino, Milán Ivelic, Adriana Valdés, Jaime Concha y Diamela Eltit. Una cuarta parte, titulada "Testimonio de creadores" con textos de Eduardo Carrasco, Ramón Diaz Eterovic y Rodrigo Torres y por último, la sección Redemocratización y política cultural con las exposiciones de Manuel Antonio Garretón, Eugenia Tironi, Enrique Barros, Cristian Cox y Agustín Squella. Véase Sosnowski, Garretón \& Subercaseaux (1993). 
energías que se expresaron con fuerza en el mundo cultural "parecieran agotarse y subsumirse en el mundo reconocido de la política" entendida la política como el mundo de la negociación, la concertación y la búsqueda de consenso, que conducía a la "atenuación del debate cultural para evitar cualquier riesgo (real o imaginario) de regresión autoritaria" (SOSNOWSKI, GARRETÓN \& SUBERCASEAUX, 1993: 9).

Es así que esta introducción, que de algún modo ofició de síntesis de lo discutido en el encuentro, ponía de manifiesto la tensión entre la cultura y la democracia, que no era nueva, pero que habría adquirido nuevos sentidos y que era abiertamente tematizada por los participantes. En el apartado comparado del encuentro uruguayo Corradi también había advertido sobre el peligro del consenso para el desarrollo de la cultura. Afirmaba que si se pretendían aplicar al terreno de la producción cultural los mismos principios que regulaban la conducta en una democracia política, el consenso se convertiría en una prevención del conflicto y la cultura pagaría el precio de la chatura y el aburrimiento (CORRADI, 1987: 296). En la misma línea, pero de un modo más incisivo, Nelly Richard, directora de la Revista de Crítica Cultural, ${ }^{15}$ sostenía que: "La paradoja misma de la diferencia misma como valor crítico pasa muchas veces al servicio de una especie de pluralismo conformista, en el que las diferencias son llamadas a coexistir pasivamente bajo un régimen neutral que las alinea a todas por igual, refugiándose tras la moral reconciliadora-y conciliadora- de la suma" (RICHARD, 1993: 44).

Esta preocupación por las ventajas pero también los nuevos problemas e interrogantes que inauguraba la democracia fue común a varias intervenciones $y$, en un segundo encuentro que se realizó como continuador del de Maryland pero en la Universidad de Valparaíso, muchas de estas cuestiones volvieron a ser tematizadas, fundamentalmente el problema del consenso de la democracia. ${ }^{16} \mathrm{Si}$ por un lado, el

\footnotetext{
${ }^{15}$ La Revista de Crítica Cultural (Santiago de Chile, mayo 1990- diciembre 2007) fue una publicación trimestral dirigida por Nelly Richards (teórica y crítica de arte) y en su consejo editorial colaboraron hasta 1995: Juan Dávila (artista y escritor), Eugenio Dittborn (artista visual) Diamela Eltit (escritora y ex miembro de CADA, Colectivo de Acciones de Arte), Carlos Pérez (filósofo), Adriana Valdéz (ensayista y crítica) y Carlos Altamirano (artista plástico). Sus 36 números proponían, desde una arena interdisciplinaria, intervenir de un modo crítico en los debates culturales acompañando el desembarco democrático hasta su consolidación generando un espacio alternativo y transdisciplinar.

${ }^{16} \mathrm{El}$ encuentro contó con 4 paneles. El primero titulado Poder, mercado y felicidad del que participó Ricardo Moreno. El segundo se llamó Creación y cultura de masas y se publicaron las ponencias de Nelly Richards, Eugenio Tironi y Fernando Rosas. El tercero: Modernidad, pasión, razón, memoria y contó con Martín Hopenhayn, Raquel Olea y Francisco Sazo. El último se denominó Identidad: provincia, nación o planeta y expusieron: Carlos Aldunate, Sonia Montecino y Ricardo Larraín. Cerró el encuentro Manuel
} 
diálogo y el acuerdo eran vistos como constitutivos al desarrollo democrático, por el otro, ese consenso atentaba contra la crítica y la discusión, a su vez tan necesarias para el desarrollo de la cultura y la labor intelectual. Para Richard, la pregunta consistía en “¿cómo hacer que lo plural y lo múltiple no sean variedad indiferenciada, sino juego contrastado de variantes diferenciadoras?” (RICHARD, 1994: 51). En la misma línea para el sociólogo Eugenio Tironi la transición democrática no era una época propicia para la cultura porque "el orden y el equilibrio limitan severamente la libertad para discrepar, para inventar, para creer" (TIRONI, 1994: 57). De este modo, varios autores advirtieron sobre la nueva paradoja que entrañaba el consenso de la democracia: si por un lado revertía la imposición autoritaria de la única voluntad a la que tan acostumbrados estaban los latinoamericanos bajo las dictaduras militares, por el otro establecía un límite a la crítica y al debate en pos de un acuerdo que aparecía como avasallador y "poco pluralista”. Esta situación evidenciaba la tensión a la que estuvo sujeta la cultura en la redemocratización y que emergió, quizás como signo de los tiempos asociados a la posmodernidad y al quiebre de las certezas, también en el encuentro de los paraguayos.

\section{Paraguay y la invención democrática}

El último encuentro se tituló: "Hacia una cultura de la democracia en el Paraguay" y cristalizó varias de las cuestiones que venían discutiéndose, en clave de paradojas o contradicciones, en los otros encuentros. ${ }^{17}$ Paraguay se independizó de la metrópolis de un modo particular, bajo la figura de una dictadura perpetua -la de José Gaspar Rodríguez de Francia- y se democratizó también de un modo singular: la

\footnotetext{
Antonio Garretón. El libro también contó con la Ceremonia de Inauguración del seminario en la que fueron oradores: el rector de la Universidad de Valparaíso Agustín Squellá, el Ministro de Educación Jorge Arrate y Saúl Sosnowski. Véase Sosnowski et al. (1994).

${ }^{17}$ El encuentro tuvo lugar entre el 17 y el 19 de abril de 1994. La presentación del libro estuvo a cargo de Saúl Sosnowski, Augusto Roa Bastos y Benjamín Arditi y el libro constó de cinco apartados temáticos que, respetando la estructura de las publicaciones anteriores, reunieron las intervenciones. Una primera parte: Producción cultural y tradición autoritaria en la que participaron: Domingo Rivarola, Guido Rodríguez Alcalá, Bartomeu Meliá. Segunda parte: Transgresores, conquistadores y constructores de una sociedad con escritos de Carlos Colombino, Line Barreiro, Gloria Rubín y Osvaldo Salermo. Una tercera parte: El cambio se vino de golpe. Ponencias de Marcial Riquelme, Diana Serafini, Lorraine Ocampos. Cuarta Parte: Perspectivas desde la gestión cultural. Raúl Sapena Brugada, Gerardo Fogel y Ticio Escobar. Quinta parte: Propuestas: políticas culturales para la democracia. José Carlos Rodriguez, Ramiro Dominguez y Juan Andres Cardozo. Véase Sosnowski, Barreiro \& Escobar (1994).
} 
dictadura de Alfredo Stroessner, que gobernaba desde 1954 y durante siete períodos presidenciales, fue derribada por otro golpe militar el 2 de febrero de 1989 liderado por el General Andrés Rodríguez también perteneciente al mismo partido Colorado. A diferencia de los otros tránsitos de la región, la democracia en Paraguay no parecía tener antecedentes y había sido el resultado del autogolpe de una facción militar.

El prestigioso politólogo Benjamín Arditi explicitó el desafío de construir ex nihilo a la democracia. Enfatizó por un lado, el carácter fundacional de la transición junto a la necesidad de construir, a modo de invención, una democracia capaz de desestructurar el stronnismo, y por el otro, la dificultad de romper de forma clara y decisiva con el pasado. Frente a la consabida afirmación de que toda transición se caracteriza por una combinación de continuidades y rupturas, la posibilidad de la democracia en Paraguay descansaba para Arditi en que el pasado no fuera un determinante sino una posibilidad entre otras y que el proceso estuviera mucho más marcado por la indeterminación e indecidibilidad de la democracia (ARDITI, 1994: 41).

A esta situación de persistencia del pasado en el presente se sumaba una particularidad contemporánea. En palabras de Ticio Escobar la transición había "sintonizado con un momento especial de los tiempos modernos marcado por el desencanto y las posturas light, el abandono de los sueños emancipatorios y el descrédito de las utopías." (ESCOBAR, 1994: 215). Es así que el surgimiento de la pluralidad y la diferencia como marcas de la naciente democracia actuaban de forma ambigua tendiendo tanto "a reforzar un entramado social más complejo y resistente como a entibiar las certezas colectivas y arriesgar la idea de un proyecto global compartido" (ESCOBAR, 1994: 217). Lo que afirmaba Escobar es que la transición coincidía con un momento en que la nueva sensibilidad descreía de las totalizaciones y las grandes síntesis y proponía en cambio, un nuevo paisaje entrecortado y disperso, fracturado y revuelto. En este escenario difícilmente la democracia podía construir un "nosotros" o un cimiento para la cohesión social y la integración. Es así que el dilema no era tanto la dificultad de expresar las diferencias sino de generar identidad.

En síntesis, la democracia debía construir identidad pero como resultado de posiciones variables que difícilmente construían un nosotros, debía integrar un paisaje disperso y fracturado pero descreyendo de las totalizaciones y debía actuar desde el desprestigiado Estado para reconstruir la independiente sociedad civil. El gran desafío de las políticas culturales era entonces superar la oposición por un lado entre la unidad, la cohesión social y la identidad, y por el otro, la diversidad, el pluralismo y la 
diferencia. Una tarea difícil pero no por ello imposible. En ese sentido, si bien el pasado autoritario era visto como un peligro por lo arraigado que se encontraba en la cultura del Paraguay y por ende se desconfiaba de la posibilidad de construir una cultura democrática, había cierta esperanza u optimismo. A diferencia del encuentro chileno, para Line Bareiro, el consenso democrático no debía ser interpretado como uniformidad de criterio sino como administración eficiente de conflictos y por ello tampoco debía ser asumido como incompatible con la construcción de una cultura democrática (BAREIRO, 1994).

Si los intelectuales chilenos reforzaron la idea de la fragmentación frente al bálsamo arrollador de la unidad, en Paraguay parecía necesario primero afianzar la unidad y desde allí trabajar por una política cultural democrática. Una unidad que también aparecía como una necesidad para la construcción democrática en el encuentro argentino, pero que se enfrentaba a una tradición política antinómica y autoritaria.

\section{Los intelectuales de Maryland: palabras finales}

Más allá de las diferencias -por el contexto político e intelectual que signó la década transcurrida entre el primer y el último encuentro, y la impronta de las particularidades nacionales en los debates- los cinco encuentros de Maryland, de los que participaron países que se identificaron con la región conosureña, partieron de una situación común: finalizaron las dictaduras militares, tuvieron lugar elecciones más o menos libres, y se llamó a la restauración democrática. Este punto de partida dio lugar, como vimos en las páginas anteriores, a ciertos debates comunes y a problematizaciones compartidas en torno al proceso que se iniciaba -con sus tensiones y límites-y al lugar que le cabía a la cultura y los intelectuales, no exento también de estas tensiones y limitaciones.

Los reunidos enfatizaron que debieron (re)aprender el trato con una institución que pasó de autoritaria a conciliadora y de represiva a dialogante, para Richard supuso "pasar de la política del antagonismo a la política de la transacción” situación que "no podía sino traer desconciertos y redefiniciones político-culturales" (RICHARD, 1993: 39). Un camino complejo porque para algunos, curiosamente, había sido más fácil intervenir en dictadura que en democracia, ya que en la oposición a la dictadura los intelectuales habían encontrado identidad. Es por ello que Sosnowski sostuvo que frente 
a la dificultad de articular una estrategia cultural en democracia, quizás algunas estrategias de la antigua oposición merecían ser recuperadas (SOSNOWSKI, 1993).

Pero también los intelectuales debieron aprender a operar bajo las coordenadas de la democracia y restituir la capacidad dialógica "luego de la imposición de un único portavoz como expresión simbólica y real del poder autoritario" (SOSNOWSKI, 1994: 30). En este sentido si bien el llamado era al diálogo y al intercambio, ese camino no fue fácil ya que "fieles a las lecciones de un nacionalismo decimonónico muchos intelectuales subrayaron la singularidad de sus respectivos países", reeditaron gestos autoritarios e intolerantes, y mitos de excepcionalidad (SOSNOWSKI, 1993: s/n). Para quien coordinara todos los encuentros: "Lo sorprendente es que la renovada adopción de mitos y lemas se reproducía en intelectuales que, tanto en múltiples exilios como dentro del país, conocieron otro nivel de solidaridad regional y continental" (SOSNOWSKI, 1993: s/n). Se manifestaba de este modo algo que se repite en todos los encuentros: la persistencia del pasado y del autoritarismo arraigado en las prácticas culturales. Y junto a esta persistencia se demostraban las dificultades tanto en el plano de la política como de la práctica intelectual de emprender un cambio.

La presencia del pasado es claramente un tópico recurrente en los trabajos sobre la transición democrática y también un tema central en los debates de Maryland. No podía ser de otra manera ya que, como desarrollamos, el punto de unión y convergencia entre los países del Cono Sur, estuvo dado por ese tránsito a la redemocratización de sus instituciones y su cultura, que partía también de una situación presentada como común: el pasado dictatorial y autoritario. En los distintos encuentros convivieron intervenciones más teleológicas que se refirieron al pasado como un resabio que iría desapareciendo al compás de la consolidación democrática o una contradicción que podría resolverse en democracia, con otras perspectivas más críticas que, asumiendo el carácter contingente e incierto del proceso que se iniciaba, enfatizaban la imposibilidad de eliminar el pasado entendido más bien como un elemento constitutivo de las nuevas democracias.

Ahora bien, reconocer esta evocación del pasado como aquello que conecta o vincula a los encuentros -en clave de continuidad o ruptura-, nos parece una vía muy explorada y poco prometedora. Si bien el pasado aparece como un tópico recurrente en todos los encuentros, lo que nos parece singulariza y conecta las experiencias no es tanto su presencia sino más bien la trama argumental en la que el pasado se inscribe y 
que hace que el mismo aparezca de un modo incómodo y disruptor en el presente democrático.

En este sentido creemos, y es esta nuestra intuición en la que seguiremos trabajando, que la paradoja -entendida como una figura retórica de oposición que consiste en emplear expresiones o frases que implican contradicción o que se muestran irreconciliables en la medida que posibilitan que un discurso vaya en dos sentidos a la vez-, es la figura que articula los sentidos de la democracia en esos años. ${ }^{18} \mathrm{Si}$ afirmamos que el lenguaje de la democracia se caracteriza por ser un lenguaje paradójico (o paradojal), es porque creemos que la paradoja es la figura que más se acerca a explicar lo problemático y conflictivo del pensamiento político de esos años al desnudar sus tensiones inherentes bajo las formas de consensos conflictivos, unidades plurales, mitos reales y memorias olvidadas, y también, porque los intelectuales tematizaron el problema de la democracia de la transición en clave paradojal.

Para finalizar, como sostiene Deleuze, "la fuerza de las paradojas reside en esto, en que no son contradictorias, sino que nos hacen asistir a la génesis de la contradicción” (DELEUZE, 1994: 92) y por ello resultan sugerentes para pensar las redemocratizaciones. En la medida que la paradoja evidencia el carácter problemático de las nacientes democracias por su carácter incierto, contestable e indeterminado, explica por qué, aún hoy, las transiciones son un tópico actual y debatible.

\section{Referencias bibliográficas}

ACHÚGAR, Hugo (1987). Las orillas de los exilios. En: SOSNOWSKI, Saúl. La cultura uruguaya: represión, exilio y democracia. Montevideo, Ediciones de la Banda Oriental, pp. 241-247.

ARDITI, Benjamín (1994). Cálculo y contingencia en las transiciones a la democracia. En: SOSNOWSKI, Saúl, BARREIRO, Line \& ESCOBAR, Ticio (eds.). Hacia una cultura para la democracia en el Paraguay. Asunción: Dirección de cultura, Municipalidad de Asunción y Centro de Documentación y Estudios, pp. 25-45.

BAREIRO, Line (1994). Hilos Enredados. En SOSNOWSKI, Saúl, BARREIRO, Line \& ESCOBAR, Ticio (eds.). Hacia una cultura para la democracia en el Paraguay. Asunción: Dirección de cultura, Municipalidad de Asunción y Centro de Documentación y Estudios, pp. 99-109.

\footnotetext{
18 Varias de estas ideas fueron discutidas con Ariana Reano en un trabajo conjunto que venimos realizando sobre el lenguaje político de los años ochenta.
} 
BAYLY, Christopher Alan et al. (2006). AHR Conversation: On Transnational History. The American Historical Review, volumen 111 (5). Chicago: University of Chicago Press, pp. 1441-1464.

CONRAD, Sebastian (2016). What is global history? Princeton: Princeton University Press.

CORRADI, Juan (1987). Dilemas culturales de la consolidación democrática en Argentina. En: SOSNOWSKI, Saúl. La cultura uruguaya: represión, exilio y democracia. Montevideo, Ediciones de la Banda Oriental.

DASSIN, Joan (1987). Aspectos culturales de la transición brasileña. En: SOSNOWSKI, Saúl. La cultura uruguaya: represión, exilio y democracia. Montevideo, Ediciones de la Banda Oriental, pp. 305.

DE DIEGO, José Luis (2001). ¿Quién de nosotros escribirá el Facundo? Intelectuales y escritores en Argentina (1970-1986). La Plata: Ediciones Al Margen.

DE GIORGI, Álvaro (2010). Pasado reciente y mitologías (re)fundacionales en el Uruguay. Un análisis de los discursos presidenciales de Julio María Sanquinetti (1985) y Tabaré Vazquez (2005-2006). En BOHOSLAVSKY, Ernesto et al. Problemas de Historia Reciente del Cono Sur. Buenos Aires: PrometeoUniversidad Nacional de General Sarmiento, pp. 147-169.

DELEUZE, Gilles (1994). Sobre la paradoja. Lógica de sentido. Barcelona: Paidós.

DE LOYOLA BRANDAO, Ignacio (1994). Literatura e Resistencia. En SOSNOWSKI, Saúl \& SCHWARZ, Jorge. Brasil: O Trânsito da memória. Sao Paulo: EDUSP, pp. 175-184.

DE SOUZA NEVES, Margarita \& ROLIM CAPELATO, María Helena (2008). Retratos del Brasil: ideas, sociedad y política. En TERÁN, Oscar (comp.) Ideas en el Siglo. Intelectuales y cultura en el siglo XX latinoamericano. Buenos Aires: Siglo XXI, pp. 99-208.

ESCOBAR, Ticio (1994). La cultura después del desencanto. En SOSNOWSKI, Saúl, BAREIRO, Line \& ESCOBAR, Ticio (eds.) Hacia una cultura para la democracia en el Paraguay. Asunción: Dirección de cultura, Municipalidad de Asunción y Centro de Documentación y Estudios, pp. 213-222.

FEINMANN, Juan Pablo (2014). Política y verdad. La construcción del poder. En SOSNOWSKI, Saúl (ed.) Represión y reconstrucción de una cultura: el caso argentino. Buenos Aires: Eudeba, pp. 113-133.

GALEANO, Eduardo (1987). La dictadura y después. Las heridas secretas. En: SOSNOWSKI, Saúl. La cultura uruguaya: represión, exilio y democracia. Montevideo, Ediciones de la Banda Oriental, pp. 107-125.

GARATEGARAY, Martina (2018). Unidos, la revista peronista de los ochenta. Bernal: Editorial de la Universidad Nacional de Quilmes.

\& REANO, Ariana (2019-2020). La transición democrática en debate. Una propuesta teórico-metodológica para el análisis de las transiciones $\begin{array}{llll}\text { latinoamericanas. } & \text { Revista } & 49 .\end{array}$ http://izquierdas.cl/ediciones/2020/numero-49.

\& REANO, Ariana (2018). La democracia como lenguaje político de la transición. Avances en la construcción de una perspectiva de análisis. Prismas Revista de Historia Intelectual, número 22: 31-50.

\& REANO, Ariana (2017). Apuntes para una historia intelectual de la transición democrática. A Contracorriente, volumen $14 \quad$ (2): 262-279. http://acontracorriente.chass.ncsu.edu/index.php/acontracorriente/article/view/158 0 . 
GORELIK, Adrián (2004). El comparativismo como problema: una introducción. Prismas Revista de Historia Intelectual. Bernal: Universidad Nacional de Quilmes, número 8: 121-128.

GREGORICH, Luis (2014). Literatura. Una descripción del campo: narrativa, periodismo, ideología. En SOSNOWSKI, Saúl (ed.) Represión y reconstrucción de una cultura: el caso argentino. Buenos Aires: Eudeba, pp. 153-172.

HEKER, Liliana (2014). Los intelectuales ante la instancia del exilio: militancia y creación. En SOSNOWSKI, Saúl (ed.) Represión y reconstrucción de una cultura: el caso argentino. Buenos Aires: Eudeba, pp. 261-268.

KAUFMAN, Edy (1987). El rol de los partidos políticos en la redemocratización del Uruguay. En: SOSNOWSKI, Saúl. La cultura uruguaya: represión, exilio y democracia. Montevideo, Ediciones de la Banda Oriental, pp. 25-62.

KOVALDOFF, Santiago (2014). Por un futuro imperfecto. En SOSNOWSKI, Saúl (ed.) Represión y reconstrucción de una cultura: el caso argentino. Buenos Aires: Eudeba, pp. 303-307.

LASTRA, María Soledad (2018). La Historia comparada y sus desafíos para interrogar el pasado reciente del cono sur. Revista de Historia Comparada, volumen 12 (2), pp. 139-171.

PALTI, Elías (2005). De la historia de "ideas" a la historia de los "lenguajes políticos" las escuelas recientes de análisis conceptual: el panorama latinoamericano. Anales, $\mathrm{n}^{\mathrm{o}} 7-8$.

(2018). Una arqueología de lo político. Regímenes de poder desde el Siglo XVII. Buenos Aires: Fondo de Cultura Económica.

PERELLI, Carina (1987). El poder de la memoria, la memoria del poder. En: SOSNOWSKI, Saúl. La cultura uruguaya: represión, exilio y democracia. Montevideo, Ediciones de la Banda Oriental.

RIAL, Juan (1987). El imaginario social. Los mitos políticos y utopías en el Uruguay. Cambios y permanencias durante y después del autoritarismo. En: SOSNOWSKI, Saúl. La cultura uruguaya: represión, exilio y democracia. Montevideo, Ediciones de la Banda Oriental, pp. 63-89.

RICHARD, Nelly (1993). En torno a las diferencias. En: SOSNOWSKI, Saúl, GARRETÓN, Manuel Antonio \& SUBERCASEAUX, Bernardo (eds.) Cultura, autoritarismo y redemocratización en Chile. Santiago: FCE.

(1994). Crítica cultural y debate democrático. En: V/A Cultura y sociedad. Encuentro y desencuentros. Cultura y sociedad. Encuentro y desencuentros. Chile: Editorial de Universidad de Valparaíso, p. 49-54.

SARLO, Beatriz (2014). El campo intelectual: un espacio doblemente fracturado. En SOSNOWSKI, Saúl (ed.) Represión y reconstrucción de una cultura: el caso argentino. Buenos Aires: Eudeba, pp. 135-151.

SOSNOWSKI, Saúl (ed.) (1985) (2014) Represión y reconstrucción de una cultura: el caso argentino. Buenos Aires: Eudeba Sosnowski,

SOSNOWSKI, Saúl (1987a). La cultura uruguaya: represión, exilio y democracia. Montevideo, Ediciones de la Banda Oriental.

(1987b). Dentro de la otra orilla. La cultura uruguaya: represión, exilio y democracia. En SOSNOWSKI, Saúl (ed.) La cultura uruguaya: represión, exilio y democracia. Montevideo: Ediciones de la Banda Oriental, pp. 11-22.

(1993). Cultura, autoritarismo y redemocratización. Revista de Crítica Cultural, 6: $\mathrm{s} / \mathrm{n}$.

(1994). Ni centro ni periferia: análisis de represión y reconstrucción de la cultura en el Cono Sur. En: V/A Cultura y sociedad. Encuentro y desencuentros. Cultura 
$y$ sociedad. Encuentro y desencuentros. Chile: Editorial de Universidad de Valparaíso, pp. 25-38.

(2014). "treinta años algo son”. En SOSNOWSKI, Saúl (ed.) Represión y reconstrucción de una cultura: el caso Argentino. Buenos Aires: Eudeba,pp. 9-17. ., BAREIRO, Line \& ESCOBAR, Ticio (eds.) (1994). Hacia una cultura para la democracia en el Paraguay. Asunción: Dirección de cultura, Municipalidad de Asunción y Centro de Documentación y Estudios.

. \& SCHWARZ, Jorge (1994). Brasil: O Trânsito da memória. Sao Paulo: EDUSP. GARRETÓN, Manuel Antonio \& SUBERCASEAUX, Bernardo (eds.) (1993). Cultura, autoritarismo y redemocratización en Chile. Santiago: FCE.

GARRETÓN, Manuel Antonio \& SUBERCASEAUX, Bernardo (eds.) (1993). Presentación. En: SOSNOWSKI, Saúl, GARRETÓN, Manuel Antonio \& SUBERCASEAUX, Bernardo (eds.) Cultura, autoritarismo y redemocratización en Chile. Santiago: FCE.

SOSNOWSKI, Saúl, et al. (1994). Cultura y sociedad. Encuentro y desencuentros. Chile: Editorial de Universidad de Valparaíso.

TAVARES, Maria da Conceição (1994). A política economica do autoritarismo. En: SOSNOWSKI, Saúl \& SCHWARZ, Jorge, Brasil: O Trânsito da memória. Sao Paulo: EDUSP, pp. 19-30.

TIRONI, Eugenio (1994). Sobre el orden y la aventura. En: V/A. Cultura y sociedad. Encuentro y desencuentros. Chile: Editorial de Universidad de Valparaíso, pp. 5558.

VELHO, Gilberto (1994). Autoritarismo e violencia no Brasil contemporáneo. En SOSNOWSKI, Saúl \& SCHWARZ, Jorge. Brasil: O Trânsito da memória. Sao Paulo: EDUSP, pp. 31-40.

WEINSTEIN, Martin (1987a). Decadencia y caída de la democracia en Uruguay. Lecciones para el futuro. En: SOSNOWSKI, Saúl (ed.) La cultura uruguaya: represión, exilio y democracia. Montevideo: Ediciones de la Banda Oriental, pp. 91-106.

YÁNEZ, Rubén (1987b). La represión de la cultura uruguaya. Por su nueva función en torno al Programa Popular ante la crisis. En SOSNOWSKI, Saúl (ed.) La cultura uruguaya: represión, exilio y democracia. Montevideo: Ediciones de la Banda Oriental, pp. 141-155.

Artigo recebido em 12 de novembro de 2019

Aprovado em 30 de novembro de 2019.

DOI:10.12957/intellectus.2019.47129 